\title{
Знания и инновации как условие прогресса общества: вызовы, возможности, тенденции развития
}

\author{
Макешина Юлия \\ Приднепровская академия физической культуры и спорта, Днепр, Украина
}

\begin{abstract}
АННОТАЦИЯ
Актуальность темы исследования в том, что быстрое расширение научных знаний является ключевым фактором в поддержании развития прогресса общества. Технологические инновации, учтенные как результат быстрого повышения благосостояния, становятся важным инструментом в разработке пока недоступных ресурсов. Социальные медиа, мобильная связь, и технологии обработки больших данных - ключевые компоненты сотрудничества негосударственных субъектов и правительств. Цель исследования- концептуализация знаний и инноваций как условия прогресса общественно-политического и экономического развития общества. Задачи исследования: 1) анализ развития информационных технологий как новой тенденции, которая влияет на развитие современного мира; 2) формирование человеческого капитала как условие прогресса общественно-политического и экономического развития общества; 3) прогрессивный сценарий общественно-политического и экономического развития общества; 4) формирование креативного класса как фактор развития информационно-коммуникационных технологий. Методы исследования наблюдение и фиксация в терминах, принятых в науке, наиболее значимых черт, проявлений развития общества; систематизированное обобщение разнообразных эмпирических данных, сведений, отражающих различные стороны и состояния объекта; анализ и синтез информации, метод системности, которые помогли привести к целостности исследуемого объекта. Результат исследования. Доказано, что информационные технологии входят в эпоху больших данных. Операционные процессы и банки данных становятся почти бесплатными; сетевые и облачные технологии обеспечивают глобальный доступ и повсеместным услугам; социальные СМИ и сфера кибер-безопасности становятся новыми большими рынками. Три технологических направления изменяют наш образ жизни, порядок ведения дел и безопасность: технологии в области хранения и обработки больших массивов данных; технологии социальных сетей; «умные города» как множество городских технологий, работающих с помощью обновленных и безопасных IT-систем. Продвижения в сфере хранения и обработки больших данных предвещают назревающий экономический бум, достижения во множестве технологий формируют гигантские инвестиции в инфраструктуру «умных городов».

Ключевые слова: знания, инновации, прогресс, информационно-компьютерные технологии, человеческий капитал, креативный класс.
\end{abstract}

\section{ВВЕДЕНИЕ}

Актуальность темы исследования, что в основе знания, инноваций как условия прогресса общественно-политического и экономического развития общества лежат информационные технологии. Homo sapiens - новый вид, который использует знания, информацию, науку, информационные технологии, чтобы противостоять энтропии и преодолению нестабильности. Люди во всем мире развивают знания о ландшафте своего существования, флоре и фауне, общественном и политическом развитии общества, чтобы противостоять разрушениям природы, человеческой цивилизациии, для чего усовершенствуют свои технологии, углубляют и расширяют знания, инновации, содействующие прогрессу общества. Сегодня знания человечества неустанно расширяются и поэтому нужны новые пути, которые бы систематизировали и делали их доступными. В этом нам помогают компьютеры, которые есть результатом нагромождения наших знаний в электронике и других сферах цифровой революции, а нагромаждение знаний служит основой прогресса общества, образования, науки. В развитых и развивающихся странах формируется креативный класс - 
люди творческого труда, создающие инновации и обеспечивающие конкурентные преимущества в соревновании экономик XXI века (Andriukaitiene и др. 2019).

Цель исследования - концептуализация знаний и информации как условия прогресса общественно-политического и экономического развития общества.

Задачи исследования: 1) анализ развития информационных технологий как новой тенденции, которая влияет на развитие современного мира; 2) формирование человеческого капитала как условие прогресса общественно-политического и экономического развития общества; 3) прогрессивный сценарий общественно-политического и экономического развития общества; 4) формирование креативного класса как фактора развития информационно-коммуникационных технологий.

Методы исследования - наблюдение и фиксация в терминах, принятых в науке, наиболее значимых черт, проявлений развития общества; систематизированное обобщение разнообразных эмпирических данных, сведений, отражающих различные стороны и состояния объекта; анализ и синтез информации, метод системности, которые помогли привести к целостности исследуемый объект.

\section{РЕЗУЛЬТАТ ИССЛЕДОВАНИЯ}

\section{1. Развитие информационных технологий как новая тенденция, которая влияет на развитие современного мира}

Сегодня возникают новые тенденции, которые влияют на развитие современного мира: 1) глобальная экономика, которая приводит к глобальной нестабильности и углублению противоречий в экономических интересах, а такж пандемия COVID-19; 2) угрозы управлению, так как правительства и государственные институты не могут достаточно быстро адаптироваться к изменениям существующей системы в результате пандемии; 3) потенциал нарастания конфликтов, которые не могут привести к быстрым изменениям во власти; 4) расширение границ региональной нестабильности на Ближнем Востоке и в Южной Азии, которые могут перекинуться на другие регионы; 5) влияние новых технологий, которые свидетельствуют о том, что появяются технологические прорывы для экономической эффективности в решении проблем, вызванных ростом мирового населения, быстрой урбанизацией и изменениями климата. В то же время технологии могут иметь обратный эффект: низко- и среднеквалифицированные сотрудники производства окажутся ненужными для развитых экономик, что усилит социальное неравенство. Это требует качественно иного подхода к развитию знаний и информации как условия прогресса общественно-политического и экономического развития общества (Воронкова и др. 2020а).

\section{2. Формирование человеческого капитала как условие прогресса общественно-поли-} тического и экономического развития общества

Задача восстановления и закрепления преимуществ в области образования и культуры является первоочередной задачей для стратегии развития как с позиции обеспечения, экономического роста, так и для устойчивости образовательной, культурной, социальной политики. Поддержание развития человеческого капитала в таких сферах, как урбанистика, экология, транспорт, информационное пространство, медицина, социальная помощь, ЖКХ в значительной степени 
превышает отставание в сфере материального производства и промышленных технологий, что требует внедрения менеджмента культуры (Žukauskas, Vveinhardt \& Andriukaitienė, 2018). Именно в области человеческого капитала сосредоточены, если не брать в расчет природные богатства, основные социально-экономические преимущества в глобальной экономике. Человеческий капитал является одним из важнейших факторов социально-экономического развития, стратегическим ресурсом, приобретают первостепенную роль в развитии инноваций, повышении производительности труда и конкурентоспособности, диверсификации экономики и стимулировании деловой активности, способствуя тем самым повышению качества жизни людей. Одной из приоритетных политических задач на данном этапе развития является развитие информационного общества и формирование электронного правительства. Необходимо широкомасштабное использование ИКТ во всех сферах жизни - здравоохранении, образовании, науке, культуре, обеспечении безопасности, промышленности, сельском хозяйстве, банковской деятельности, управлении общественными финансами и в других сферах, что требует развития человеческого капитала. (Oleksenko, 2019). Скорость и качество обратной связи между властью и обществом, технологическое расширение гарантий свободы слова важны для развития политической системы и эффективного управления на всех уровнях - национальном, региональном и местном. Для этого необходима программа разработки «прорывных» технологий - наноиндустрии, биотехнологий, медицинской техники, электротехники, приборостроения, информационных услуг государства, технологической модернизации, расширения спектра высококачественных инновационных общественных услуг. В основе развития знаний и инноваций должна быть модернизация системы образования (в первую очередь естественнонаучного и профессионального), укрепления инженерных школ, высшего и среднего профессионального образования и профессиональной ориентации; развитие в рамках программ (стандартов) среднего и высшего образования, развития креативных форм деятельности, обеспечивающих решение творческих задач в области науки и технологий; стимулирование интеграции учебного и научного (инженерного) процессов в вузах; поддержка институтов, обеспечивающих всеобщую доступность качественного образования, включая высшее (Punchenko и др. 2019). Это делает инновации сугубо технологическим явлением, что заведомо ограничивает пространство выбора решений. Более предпочтительной является установка на распространение инноваций во всех секторах (высоко-, средне- и низкотехнологичных). Именно в последних двух сегментах может быть достигнут наиболее масштабный эффект от их распространения, охватывающих всю экономику и широкие слои общества (Воронкова и др. 2021b). Стимулирование инновационной активности и формирование инновационного сектора необходимо как для поддержания конкурентоспособности товаров и услуг в условиях глобального рынка, так и для перехода к следующей инновационной стадии развития, позволяющей привести в соответствие качество человеческого капитала и структуру экономики, а также смягчить негативные факторы, ограничивающие потенциал роста экономики сегодня. Для этого следует развивать инновационное производство и его основные сценарии с учетом глобальных технологических изменений (начало новой технологической «волны» с фокусом на масштабном тиражировании улучшающих инноваций) и возможных вариантов трансформации инновационных процессов (Воронкова \& Андрюкайтене, 2020). 


\section{3. Прогрессивный сценарий общественно-политического и экономического развития} общества

В основе прогрессивного сценария общественно-политического и экономического развития лежат следующие задачи: форсированное встраивание науки в глобальную экономику на постиндустриальном этапе; комплексная реформа, разработка и внедрение инструментов стимулирования спроса на инновации и поддержки их предложения; комплексная реформа в науке с оценкой результативности научных организаций, дифференцированной по направлениям и видам инновационной деятельности; подготовка кадров для инновационной экономики, системы инженерных и научных квалификаций; фокус на техническом образовании и развитии современного рынка интеллектуальной собственности, для чего необходимо стимулирование инноваций во всех секторах экономики; создание благоприятной среды для инновационных компаний; развитие сетевой кооперации на всех уровнях и перераспределение полномочий государства в пользу регионов, институтов развития, бизнес-ассоциаций. При прогрессивном сценарии должны быть проведены более широкие мероприятия по «настройке» бизнес-среды, а наряду с государственным стимулированием активно задействованы механизмы рынка. Эффективность государственной поддержки инновационной активности должна определяться наличием конкурентных механизмов, а их развитие должно быть условием поддержки со стороны государства, В основе институциональных изменений, ведущих к построению экономики знаний, лежит развитие в обществе инновационного мышления и духа предпринимательства, которые не могут сформироваться вне креативного класса, создающего в «экономике знаний» большую часть добавленной стоимости. Именно креативный класс является носителем инновационной культуры, поэтому важнейшей задачей государства и общества должно стать создание благоприятной среды для его развития (Воронкова \& Венгер, 2020).

\section{4. Формирование креативного класса как фактора развития информационно-комму-}

\section{никационных технологий}

Создание комфортной для креативного класса среды возможно через глубокие институциональные изменения, включая построение локальных сообществ, приспособленных под его нужды. Помимо общепринятых мер, способствующих повышению ценности человеческого капитала (улучшение качества образования, поддержка фундаментальной науки и технологических бизнесов), важны меры по защите личности, прав собственности (в том числе интеллектуальной), окружающей среды. Мировая экономика по-прежнему зависит от различных региональных и национальных экономик, где наблюдается значительная разница в скоростях развития (Danilov, 2020). Несовпадающие скорости различных региональных экономик обостряют мировые дисбалансы и создают значительные помехи в деятельности правительств и международных структур. В связи с этим следует развивать знание, инновации, науку как условие прогресса общественно-политического и экономического развития общества, развития креативных технологий, начиная от дизайна и заканчивая программированием (Рижова, 2010). Так, отсутствие технологического прогресса означает, что революция в добыче углеводородов из сланцевого газа откладывается. Однако высокие технологии становятся источником возрождения, сохраняя глобализацию. Нау- 
ка и технологии США по-прежнему лидируют, но у Вашингтона растет беспокойство по поводу снижения в стране уровня образования и квалификации. Крупные и устойчивые инвестиции Китая могли бы превратить его в равного США конкурента к 2030 году. Технологии становится все более доступными сетевым международным компаниям. Чтобы удержать лидерство в ключевых сферах, все чаще нужно сотрудничать с международными партнерами. Развитие информационно-компьютерных технологий (ИКТ) привело к значительным инновациям (Nikitenko, 2019). Аддитивное производство, трехмерная печать 3D, уже используется, чтобы сделать предметы из пластмасс в таких секторах, как потребительские товары, аэрокосмическая и автомобильная промышленность. Гибкость, скорость и возможность адаптации аддитивного производства выгодны как для развитых, так и для развивающихся экономик. Промышленные роботы преобразовали многие сферы производства. Свыше 1,2 млн. промышленных роботов уже используются сегодня по всему миру. Домашние роботы пылесосят дома и подстригают газоны, больничные роботы убирают коридоры и разносят медикаменты. В армии США тысячи роботов действуют на полях сражений. Появляется новое поколение роботов для сектора услуг, включая уборку, техобслуживание и даже связи с общественностью. «Умный город» - это городская среда, которая с помощью разработок, базирующихся на информационных технологиях, позволяет довести до максимума производительность инфраструктуры и качество жизни обитателей, одновременно сводя к минимуму потребление ресурсов и природный ущерб. Со времени появления современных технологий обработки данных большие массивы выросли в размерах на порядок, а пользователи, работающие с крупными блоками открытых знаний, оперирующие большими массивами данных, отстали от такого роста - вместе с программными инструментами и опытом. Образовался большой - и стремительно растущий - разрыв между объемами данных, которые пользователи способны аккумулировать, и возможностями пользователей по эффективному применению данных (Nesterenko \& Oleksenko, 2020). В идеале искусственный интеллект, технологии визуализации данных и практика пользователей развиваются в такой степени, что люди, ищущие информацию, получают доступ к нужным сведениями в нужное время и при этом не перегружены запутывающей или ненужной информацией. Новые и развивающиеся города уже сегодня оснащены полуинтегрированной IT-инфраструктурой, обеспечивающей бесчисленное множество услуг (Nikitenko, 2020), что является результатом формирования креативного класса как фактора развития информационно-коммуникационных технологий и условия прогресса общественно-политического и экономического развития общества.

\section{ВЫВОДЫ}

Таким образом, для реализации программы развития знания и инноваций как условия прогресса общественно-политического и экономического развития общества следует:

1. Концептуализация «общества знания» как условие прогресса общественно-политического и экономического развития общества требует развития программы инновационной политики государства и выделения основных направлений ее развития. В ее основе: 1) усиление государства как модератора сетевых взаимодействий и создание инновационных кластеров, поддержка инновационных стартапов; 2) реформирование НИС в сторону большей интеграции науки, обра- 
зования и бизнеса, настройка механизмов отбора и поддержки перспективных исследований, прежде всего - конкурентоспособных на мировом рынке; 3) поддержка конкуренции, ограничение формальных и неформальных преференций различных компаний, снятие внутренних барьеров, усиление конкурентных механизмов системы государственных закупок; 4) поддержка международной кооперации фирм, их конкурентоспособности на внутреннем и внешнем рынках.

2. Программа развития знания как условия прогресса общества включает опережающее развитие конкурентоспособных на мировой арене направлений фундаментальных и поисковых исследований, современных форм организации научных исследований, развития инфраструктуры науки на прорывных направлениях и международное сотрудничество. Серьезное значение имеет развитие кооперации (в том числе сетевой) хозяйствующих субъектов при осуществлении научной, образовательной и инновационной деятельности. С учетом низкого в целом технологического уровня отечественной экономики и давления бюджетных ограничений особого внимания требует решение проблем регулирования заимствования технологий и производств. Адаптационная модель развития представляется наиболее адекватной для большинства организаций и компаний. В долгосрочной перспективе необходимо будет добиться разумного баланса между стимулированием трансфера зарубежных технологий и собственного технологического потенциала (в том числе через стимулирование кооперации отечественных компаний как с отечественными, так и с международными научными организациями и университетами). В рамках инновационной политики следует уделить внимание программам поддержки креативного класса для развития массового инновационного бизнеса, реализующего технологические инновации. Действенными инструментами могут стать различные адресные гранты, создание центров технического содействия, поддержка тематических форумов и конференций для развития партнерских связей в условиях глобализации и ее влияния на развитие технологической цивилизации (Kyrychenko, 2019).

3. С революцией в сфере высоких технологий все негосударственные учреждения, от предприятий и благотворительных организаций до университетов и научно-исследовательских центров, станут глобальными; будут процветать и занимать лидерское положение в решении глобальных проблем неправительственные организации (НПО), транснациональные компании, учебные учреждения, наднациональные структуры ввиде мегаполисов. В ближайшие 15-20 лет экономический рост в странах с формирующейся рыночной экономикой будет стимулировать распространение технологических инноваций по всему миру. Они должны будут решить двойную задачу: использовать преимущества новых информационных технологий и в то же время бороться с угрозами, которые распространяются в цифровом мире. Влияние новых технологий будет влиять на технологические прорывы, служить экономическому росту, снижению нагрузки на природные ресурсы, помогать в борьбе с последствиями изменения климата, а также с хроническими заболеваниями, старением населения и издержками стремительной урбанизации. Новая технологическая цивилизация должна служить идеалам разума, прогресса, науки. 


\section{ЛИТЕРАТУРА}

1. Andriukaitiene, R., Janulionis, E. \& Voronkova, V. (2019). The concept of corporate social responsibility and its implementation in the activity of organizations. Гуманітарний вісник Запорізької державної інженерної академії. 76, 184-199.

2. Воронкова, В., Андрюкайтене, Р. \& Никитенко, В. (2020). Влияние цифровизации на изменение ценностных ориентаций в условиях Четвертой промышленной революции. Theory and practice: problems and prospects. Scientific articles. Kaunas. 219-227.

3. Voronkova, V., Nikitenko, V., Oleksenko, R., Cherep, O., Andriukaitiene, R. \& Briki, I. (2021). Digital paradigm of economy and management in the conditions of global human transformation. Technology Transfer: Innovative Solutions in Social Sciences and Humanities, 4, 37-40. doi: http://doi.org/10.21303/2613-5647.2021.001769

4. Воронкова, В. \& Андрюкайтене, Р. (2020). Влияние технологий следующего поколения на развитие цифровой реальности. International scientific-practical conference. Theory and practice: problems and prospects. May 21-22, 2020. Kaunas. 35-36.

5. Воронкова, В. Г. \& Венгер, О. М. (2020). Формування концепції адміністративного менеджменту в умовах стрімкого розвитку технологій, стохастичності та адаптації до змін. HUMANITIES STUDIES: збірник наукових праць / Гл. ред. В. Г. Воронкова. Запоріжжя : ЗНУ, 2020. Вип. 3 (80). 159-177.

6. Danilov, A. (2020). To the technology of civilizational development: updating the cultural code content. Humanities Studies. Запоріжжя : ЗНУ. Випуск 3(80), 22-29.

7. Žukauskas, P., Vveinhardt, J., \& Andriukaitienè, R. (2018). Management Culture and corporate social responsibility. BoD-Books on Demand: IntechOpen.

8. Kyrychenko, M. O. (2019). Vplyv hlobalizatsiyi na rozvytok tsyfrovykh tekhnolohiy ta innovatsiy v umovakh chetvertoyi promyslovoyi revolyutsiyi 4.0. Humanities studies: Collection of Scientific Papers. Zaporizhzhia: ZNU. 2 (79), 39-52.

9. Nesterenko, Olena \& Oleksenko, Roman (2020). Social philosophical reflection of the individual legal education philosophy as the basis for the democratic society functioning. Humanities Studies. 3anopiжжся : 3НУ. Bunycк 4(81), $165-181$.

10. Nikitenko, V. O. (2019). The impact of digitalization on value orientations changes in the modern digital society. Humanities studies: Collection of Scientific Papers. Zaporizhzhia: ZNU, 2(79), 80-94.

11. Nikitenko, V. (2020). Evolution and further development of the real world in the conditions of technological changes in the context of socio-philosophical discourse. Humanities Studies. Запоріжжя : ЗНУ. Випуск 4(81), 60-73.

12. Oleksenko, R. (2019). Position and role of modern economic education as the main megatrend of innovative development of Ukraine. Humanities studies: Collection of Scientific Papers. Zaporizhzhia: ZNU, 2(79), 169-181.

13. Punchenko, O. \& Punchenko, N. (2019). Basic strategic technology of intellectual duality of humanity in information technology. Humanities studies: Collection of Scientific Papers. Zaporizhzhia: ZNU, 2(79), 95-114.

14. Рижова I. C. (2010). Формування потреб та інтересів в дизайнерській діяльності. Гуманітарний вісник Запорізької державної інженерної академії. Вип. 42, 247-258. 


\title{
Knowledge and Innovation as a Condition for the Progress of Society: Challenges, Opportunities, Development Trends
}

\author{
Yulia Makeshina \\ Dnieper Academy of Physical Culture and Sports Dnipro, Ukraine
}

\begin{abstract}
The relevance of the research topic is that the rapid expansion of scientific knowledge is a key factor in maintaining the development of the progress of society. Technological innovation, measured as a result of rapid increases in wealth, is becoming an important tool in the development of as yet unavailable resources. Social media, mobile communications, and big data technologies are key components of collaboration between non-state actors and governments.

The purpose of the study is to conceptualize knowledge and innovation as a condition for the progress of socio-political and economic development of society.

Research objectives: 1 . Analysis of the development of information technology as a new trend that affects the development of the modern world; 2. The formation of human capital as a condition for the progress of the socio-political and economic development of society; 3 . A progressive scenario of the socio-political and economic development of society; 4 . The formation of a creative class as a factor in the development of information and communication technologies.

Research methods: Observation and fixation in terms accepted in science, the most significant features, manifestations of the development of society; systematic generalization of a variety of empirical data, information reflecting various aspects and states of the object; analysis and synthesis of information, the method of consistency, which helped to lead to the integrity of the investigated object.

Research result: It has been proven that information technology is entering the era of big data. Operational processes and data banks are becoming almost free; web and cloud technologies provide global access and ubiquitous services; social media and cyber security are emerging as big new markets. Three technological directions are changing our way of life, the way we do business and security: technologies in the field of storage and processing of large amounts of data; social networking technologies; "Smart cities" as a multitude of urban technologies working with updated and secure IT systems. Advances in big data storage and processing herald an imminent economic boom, advances in a variety of technologies are shaping giant investments in smart city infrastructure.
\end{abstract}

Key words: knowledge, innovation, progress, information and computer technologies, human capital, creative class.

Gautas 20201215

Priimtas 20211030 